\title{
УСТОЙЧИВАЯ ТРАНСПОРТНАЯ ПОЛИТИКА
}

\author{
Алиева Улькар Н. \\ магистр Азербайджанского университета архитектуры и строительства, \\ Баку, Азербайджан
}

DOI: https://doi.org/10.31435/rsglobal_ejits/31072019/6578

\section{ARTICLE INFO}

Received 19 May 2019

Accepted 16 July 2019

Published 31 July 2019

\section{KEYWORDS}

transport infrastructure, sustainable development, green transport, pedestrian stripes, bicycle paths

\begin{abstract}
In the article "Sustainable Transport Policy", provided information about the transport policy implemented in the Republic of Azerbaijan, especially in Baku city after gaining independence. The problems in the transport system and ways of solving the problems, as well as mutual relations with international organizations are discussed. The impact of road transport on ecology is investigated and relevant recommendations are given to reduce the negative impact on the environment.
\end{abstract}

Citation: Aliyeva Ulkar N. (2019) Sustainable Transport Policy. European Journal of Intelligent Transportation Systems. 1(2). doi: 10.31435/rsglobal_ejits/31072019/6578.

Copyright: (C) 2019 Aliyeva Ulkar N. This is an open-access article distributed under the terms of the Creative Commons Attribution License (CC BY). The use, distribution or reproduction in other forums is permitted, provided the original author(s) or licensor are credited and that the original publication in this journal is cited, in accordance with accepted academic practice. No use, distribution or reproduction is permitted which does not comply with these terms.

Введение. После распада Советской Империи в начале 1990-х годов, как и на постсоветском пространстве, в Азербайджане также возникла кризисная ситуация в транспортной системе. Это побудило соответствующие власти принять кардинальные меры. Доступ к городским грузовым автомобилям был ограничен, а проекты реконструкции и развития дорожной инфраструктуры города были разработаны и реализованы, и в настоящее время они реализуются. Чтобы повысить роль общественного транспорта в городе, автобусы были приведены в соответствие с требованиями стандарта Euro 4, приняты меры по повышению эффективности пассажирских перевозок, создана система управления интеллектуальным интеллектом, административная ответственность за регулирование дорожного движения была ужесточена.

Правительство разработало Транспортную стратегию Азербайджанской Республики, направленную на развитие тенденций развития транспортной системы, основные обязанности государства в сфере транспорта, Определяя форму и содержание, установил систему общих приоритетов для транспортного комплекса.

В нем также определены приоритеты для реализации приоритетов в конкретных видах транспорта с учетом конкретных характеристик, принятие решений в области политики общественного транспорта, подготовка целевых программ в области транспорта и экономики, связанных с транспортом, в качестве ключевой ссылки на транспортно-зависимую социальную защиту и другие проблемы.

В соответствии с этой стратегией приоритетными направлениями развития инфраструктуры автомобильного транспорта являются:

- реконструкция автомобильных дорог в транспортных коридорах, проходящих через территорию страны;

- модернизация межрегиональных дорог;

- совершенствование системы управления и регулирования дорожного движения;

- модернизация автомобильной техники в соответствии с международными стандартами с точки зрения технических и экологических требований; 
- Создание и внедрение систем стандартизации и сертификации для легкового и городского пассажирского транспорта [1].

Кроме того, были определены основные принципы устойчивого развития автомобильного транспорта, которые в соответствии с этими принципами не противоречат приоритетам здоровья граждан и охраны окружающей среды и учитывают интересы будущих поколений.

Реализация этих принципов подразумевает:

- Решения о развитии транспортной системы и регулировании транспортной деятельности оцениваются с точки зрения экономической эффективности, а также с точки зрения экологии и безопасности, все отмеченные приоритеты одинаково ценны;

- Власти и граждане должны нести ответственность за выбор наилучших экологических решений в области транспорта.

- При транспортировке, прежде всего, при принятии управленческих решений в сфере автомобильного транспорта, необходимо в полной мере учитывать экологические последствия;

- в рамках принципа «платит загрязнитель» потребитель транспортных услуг должен оплачивать все негативные экологические последствия в результате рециркуляции ресурсов из их потребления;

- Регулирование трансграничной конкуренции должно регулироваться с экологической точки зрения на «более чистые» виды транспорта;

Были приняты законы Азербайджанской Республики о «Дорожном движении», «Автомобильных дорогах» и «Автомобильном транспорте» и ряд законодательных актов. Кроме того, Азербайджанская Республика расширила свои отношения с международными организациями и присоединилась к присоединились к международным договорам и конвенциям «Международные дороги», «Дорожные знаки и сигналы», «Дорожное движение» [2].

Результаты исследования. После реализации вышеупомянутые отечественные и зарубежные виды деятельности в стране началась реализация политики по созданию транспортной системы. Изначально деятельность в сфере автобусного транспорта была расширена.

Автобусное движение.

Автобусные маршруты были сокращены с 310 до 169 в результате развития и оптимизации автобусных маршрутов в Баку. Для наземного общественного транспорта было построено более 600 автобусных остановок. По сообщению ООО «Бакинский пассажирский транспорт», настоящее время на 2853 маршрутах работает около 2853, в том числе 1587 в центре, с 953 средними вместимостью и 23 небольшими автобусами на пригородных маршрутах. Интеллектуальная система управления транспортом была создана для управления автобусным движением [3].

Устойчивый транспорт (или зеленый транспорт) - это тип движения и организационная форма, которая снижает воздействие на окружающую среду. Это экономичный, экологически чистый, ориентированный на транзит дизайн, прокат автомобилей, а также городская транспортная система, которая способствует защите окружающей среды и пропаганде здорового образа жизни. Устойчивые транспортные системы вносят позитивный вклад в экологическую, социальную и экономическую устойчивость их сообщества. Транспортные системы доступны для обеспечения социальных и экономических связей.

Транспортные системы оказывают значительное влияние на окружающую среду. На их долю приходится около 20-25\% мировых отходов и выбросов серы. В результате движения парниковые газы появляются быстрее, чем в других секторах энергетического сектора. Автомобильный транспорт также является одной из основных причин возникновения местного загрязнения воздуха и дыма.

В результате дорожного движения социальные расходы включают дорожно-транспортные происшествия, загрязнение атмосферного воздуха, ослабление физической активности, увеличение времени, проведенного вне семьи во время миграции, и повышение цен на топливо.

Эти негативные результаты в основном затрагивают социальные группы, у которых нет средств для покупки и использования автомобиля. Пробки приводят к увеличению экономических затрат и дополнительным затратам времени и замедление доставки товаров и услуг.

\section{Транспорт и социальная устойчивость.}

Тот факт, что люди живут и работают в разных местах города, создал серьезные социальные проблемы. Неадекватность сети общественного транспорта в городах, плохое развитие инфраструктуры и расположение университетов, правительственных учреждений, 
банков и крупных компаний в центре города вызвали беспокойство у людей, которые приезжают туда и возвращаются домой.

Сидячий образ жизни для людей, передвигающихся на частных автомобилях, создал проблему ожирения. Это создает проблемы со здоровьем человека. В результате транспортных потоков пыль, дым и газы, выбрасываемые в атмосферу, стали серьезной угрозой для здоровья человека. В 2018 году количество отходов, перевозимых с транспортных средств в атмосферный воздух, было в 3,4 раза выше, чем у стационарных источников. Увеличение количества автомобилей, кажется, является признаком комфорта, но привело к тому, что они стали источником высоких угроз в рамках слабой инфраструктуры. Увеличение числа погибших в дорожно-транспортных происшествиях в стране ежегодно на 15-20\% создает серьезный дискомфорт для людей [4].

Основным источником газов, излучающих парниковый эффект, является транспортная система. 23\% выбросов парниковых газов транспортируется транспортной системой, а $3 / 4$ выбрасываются в атмосферу автомобильным транспортом. 95\% энергии, потребляемой автомобилем, получается из нефтепродуктов. Производство энергии также используется для транспортировки, а также в строительстве транспортной инфраструктуры - автомобильных дорог, мостов и железных дорог.

Воздействие транспорта на окружающую среду можно снизить за счет увеличения пешеходного и велосипедного движения в городах, а также за счет укрепления общественного транспорта, в частности роли железной дороги.

Экологические автомобили оказывают меньшее воздействие на окружающую среду, чем соответствующие автомобили.

Электромобили, потенциально с учетом источника электричества, приводят к снижению выбросов $\mathrm{CO}_{2}$. Гибридные автомобили уже распространены. Они достигают лучшей эффективности использования топлива. Используется в качестве топлива для двигателя с впрыском природного газа. Биотопливо все еще используется меньше, но его использование расширяется.

Результаты.

Развитие пешеходных зон.

В некоторых районах Баку целесообразно создавать территории без транспорта. Можно увеличить вместимость парковки автомобилей путем строительства существующих и дополнительных парковочных мест в границах этих территорий. Движение любых транспортных средств, за исключением пожарных, полиции, машин скорой помощи и коммунальной техники, должно быть запрещено в пешеходных зонах.

Для облегчения передвижения людей можно бесплатно организовать движение электромобилей в зонах пехоты для социально уязвимых групп (людей с ограниченными возможностями, пожилых людей, детей, пациентов) и других городских жителей.

Строительство велосипедных дорожек.

Желательно строить велосипедные дорожки во всех парках и садах города. Также возможно организовать прокат велосипедов в больших парках и садах.

Применение скоростного автобусного транспорта.

В Баку есть условия для скоростного автомобильного движения. Эти маршруты могут быть эффективными в районах, где нет линий метро.

Восстановление пригородная железная дорога (электричка).

Восстановление пригородного железнодорожного транспорта предусмотрено в концепции регионального развития Баку до 2030 года.

Восстановление трамвайных линий.

Необходимо восстановить трамвайные линии в Баку и в ближайшее время перевезти автобус из центра города. Восстановление трамвайных линий является фактором, который положительно влияет на окружающую среду города и состояние памятников истории и культуры. Удаление автобусов из центра города также позволит центру города стать деловым центром. Также желательно приобрести трамваи, произведенные известными компаниями, которые будут использоваться наряду с восстановлением инфраструктуры для трамваев в Азербайджане.

Кроме того, также желательно проводить интенсивные мероприятия для увеличения видов зеленого транспорта, перечисленных ниже. 


\section{Электротранспорт.}

Самым экологически чистым видом транспорта являются трамваи, электрические автобусы, электромобили и гибридные автомобили, работающие на электричестве и успешно используемые в городских условиях во многих странах мира.

\section{Велосипед.}

Расширение использования велосипедного транспорта в Баку должно стимулироваться государством. То есть необходимо увеличить количество велосипедных дорожек и расширить велосипедные маршруты в транспортной инфраструктуре страны. В то же время импорт и производство велосипедов должны стимулироваться государственными займами.

\section{Пешеходное движение}

Движение пешеходов помогая городскому населению предотвращать сердечно-сосудистые заболевания, также поможет предотвратить социальную нагрузку на плотность движения [5].

\section{ЛИТЕРАТУРА}

1. Q.Məmmədov, M.Xəlilov - Ekologiya və ətraf mühitin mühafizəsi - 2005

2. http://ecolex-az.org

3. http://www.niim.az

4. Мачульская, И.Г. Правовое регулирование и организация дорожного движения: зарубежный опыт

5. Dayanıqlı nəqliyyat siyasəti, Ekoleks ekoloji hüquq mərkəzi, 2016 